Carlo José Napolitano

Faculdade de Arquitetura,

Artes e Comunicação,

UNESP/Bauru/SP. Brasil.

\section{A decisão do Supremo \\ Tribunal Federal sobre a Lei de Imprensa na Folha de $S$. Paulo e no 0 Globo}

The Brazilian Supreme Court decision about the press law in Folha de $S$. Paulo and 0 Globo

La decisión de La Corte Suprema sobre la ley de prensa en La Folha de $S$. Paulo y o Globo 
RESUMO

Este trabalho é um relato de pesquisa que considera o Supremo Tribunal Federal (STF) um importante ator nas decisões políticas brasileiras. Algumas decisões do STF, por hipótese, impactaram os meios e as atividades da comunicação social, influenciando, especialmente, a forma de exercício da liberdade de expressão do pensamento e, em consequência, da democracia e da cidadania, bem como, estabeleceram critérios jurídicos que balizam a formulação e efetivação de políticas públicas de comunicação. Reconhece-se que, no âmbito estritamente jurídico, iá há uma produção científica acerca da centralidade política do judiciário, no entanto, verifica-se uma carência de estudos e análises referentes ao tratamento conferido pelos meios de comunicação em relação às decisões proferidas pelo Supremo quando relacionadas aos assuntos mencionados e suas consequências nas práticas políticas e sociais. Especificamente este trabalho visa apresentar os resultados da pesquisa junto à Folha de S. Paulo e ao O Globo relacionados à decisão do STF sobre a lei de imprensa (ADPF 130) e que indicaram que os veículos pesquisados deram pouca atenção à decisão, às funções do Supremo e à temática da liberdade de expressão do pensamento.

Palavras-chave: Supremo Tribunal Federal. ADPF 130. Folha de S. Paulo. O Globo.

\section{ABSTRACT}

This paper is a report of a research that considers the Brazilian Supreme Court (STF) as a important player in the Brazilian political decisions. Some STF decisions, by definition, impacted the media and the activities of social communication, influencing, especially the freedom of speech and, consequently, the democracy and the citizenship, as well, established legal criteria that guide the formulation and to effective communication public policies. The research also recognizes that in legal science there is a significant scientific production on political centrality of the judiciary, however, there is a lack of studies and analyzes concerning to how was the media coverage the decisions rendered by the STF and its consequences in social and politics practices. Specifically this paper aims to present the results of the research at Folha de S. Paulo and the O Globo related to the STF decision on the press law (ADPF 130), which indicated that the searched newspapers gave low emphasis to the decision, to the Brazilian Supreme Court functions and to the freedom of speech thematic.

Key-words: Brazilian Supreme Court. ADPF 130. Folha de S. Paulo. O Globo.

\section{RESUMEN}

Este texto es un informe de la investigación que considera la Corte Suprema de Justicia (STF en portugués) un actor importante en las decisiones políticas brasileñas. Algunas decisiones de la Corte Suprema, por casualidad, impactaron en los medios de comunicación y las actividades de comunicación social, especialmente, en la forma de ejercer la libertad de expresión y del pensamiento y consecuentemente en la democracia y ciudadanía, así como establecieron criterios jurídicos que sustentan la formulación y ejecución de políticas públicas de comunicación. Se reconoce que en el aspecto jurídico hay uma suficiente producción científica acerca de la centralidad de la política judicial, sin embargo, hay una falta de estudios y análisis sobre el tratamiento dado por los medios de comunicación en relación con las decisiones tomadas por el Tribunal Supremo sobre los temas mencionados y sus consecuencias en las prácticas políticas y sociales. Específicamente este trabajo tiene como objetivo presentar los resultados conseguidos en la investigación sobre la Folha de S. Paulo y O Globo relacionadas con la decisión del Tribunal Supremo sobre la ley de prensa (ADPF 130) y que indicó que los vehículos investigados dieron poca atención a la decisión, a las funciones del Supremo y al tema de la libertad de expresión del pensamiento. Palabras claves: Corte Suprema de Justicia. ADPF 130. Folha de S. Paulo. O Globo.

Submissão: 2-6-2016

Decisão editorial: 21-3-2018 


\section{Introdução}

Trata-se o presente de relato de pesquisa que partiu do pressuposto que, a partir da década de 90, o Supremo Tribunal Federal (STF) passou a exercer um papel de centralidade nas decisões políticas brasileiras, além, obviamente, de executar a sua função precípua de guardião do texto constitucional.

Algumas dessas decisões políticas do STF, por hipótese, impactaram os meios e as atividades da comunicação social, influenciando, especialmente, a forma de exercício do direito à liberdade de expressão do pensamento e, em consequência, da democracia e da cidadania, bem como, estabeleceram critérios jurídicos que balizam a formulação e efetivação de políticas públicas de comunicação.

Entre as decisões que, hipoteticamente, podem ter impactado o exercício do direito fundamental à liberdade de expressão do pensamento, podem ser citadas as decisões que aboliram do sistema jurídico brasileiro a lei de imprensa (Arguição de Descumprimento de Preceito Fundamental - ADPF 130) e a exigibilidade do diploma de jornalismo para o exercício da profissão (Recurso Extraordinário - REX 511.961), bem como, a decisão que referendou a denominada censura judicial à liberdade de informação jornalística (Reclamação n. 9.428 envolvendo o jornal O Estado de S. Paulo e Fernando José Maciel Sarney). 
Reconhece a pesquisa que no âmbito estritamente jurídico já há uma produção científica acerca da centralidade política do judiciário, em especial, do STF, no entanto, verifica-se uma carência de estudos e análises referentes ao tratamento das decisões da corte pelos meios de comunicação e suas consequências nas práticas políticas e sociais.

Considera-se que o STF é um ator importante nos processos decisórios de controle de políticas públicas, inclusive aquelas relacionadas à comunicação. Nesse sentido, a pesquisa visou investigar qual foi a abordagem dos veículos de comunicação impressos brasileiros acerca das três decisões proferidas pelo Supremo e já mencionadas, no intuito de analisar como essas decisões foram acolhidas, compreendidas e apresentadas pela mídia impressa à sociedade brasileira, em especial, no que se refere ao exercício do direito fundamental à liberdade de expressão do pensamento e a própria atuação do STF nessas questões.

A metodologia escolhida para cumprir o objetivo da pesquisa foi a análise de conteúdo de todos os gêneros jornalísticos (MARQUES DE MELO; ASSIS, 2013) produzidos pelos jornais impressos Folha de S. Paulo e $O$ Globo.

Especificamente, este trabalho visa apresentar os resultados da pesquisa obtidos junto à Folha de $S$. Paulo e ao O Globo relacionados à decisão do STF sobre a lei de imprensa (ADPF 130).

Para cumprir os seus objetivos, este trabalho está assim estruturado: apresentação de alguns apontamentos sobre a constitucionalização das políticas públicas e a consequente atuação do STF, relato do processo da ADPF 130, indicação da metodologia da pesquisa, considerações pontuais acerca 
dos achados da pesquisa e considerações gerais em sede de conclusão, que indicam que os veículos pesquisados deram pouca atenção à decisão do STF, às suas funções e à temática da liberdade de expressão do pensamento.

\section{Constitucionalização das políticas públicas e atuação do Supremo Tribunal Federal}

Os termos da constituição brasileira de 1988, com nítido teor social e econômico, de visão prospectiva, configuram uma de suas peculiaridades. O Brasil tem por tradição adotar textos constitucionais descritivos e de regulação da vida em sociedade, o de 1988 não ficou longe dessas referências.

Por esses motivos, ela é considerada por Coutinho (2013, p. 190), como sendo "progressista, generosa e transformativa", e não por acaso foi

...apelidada de 'constituição cidadã', por ter sido promulgada após um período no qual o Estado democrático de direito foi suprimido no país e por conter um respeitável rol de direitos e garantias contra o arbítrio, ela enuncia ainda um longo e detalhado capítulo de direitos econômicos e sociais. Além disso, ela contém normas ditas 'programáticas' - isto é, normas que prevêem objetivos a serem alcançados por meio de políticas públicas e comandos que explicitam valores a serem perseguidos pelo legislador infraconstitucional, juízes e administradores públicos (COUTINHO, 2013, p. 190).

Ao inserir nas normas constitucionais conteúdos de políticas públicas governamentais, atribuindo papéis ao Estado na condução da economia, mantendo-se ainda resquícios do modelo nacional desenvolvimentista, a nova sistemática constitucional implicou, segundo Arantes e Couto (2004), em alterações no 
modus operandi do sistema político brasileiro e no sistema de justiça.

Ao constitucionalizar assuntos relacionados à atividade econômica, como é o caso da Comunicação Social, o constituinte obrigou os governantes eleitos a efetivarem modificações constitucionais e legais antes de colocarem em prática os seus programas básicos de governo relacionados à economia.

Esses programas básicos podem estar traduzidos em emendas à constituição e em alterações legislativas infraconstitucionais que, potencialmente, podem passar a ser também objeto de análise por parte do judiciário brasileiro, em especial, do Supremo Tribunal Federal, órgão responsável pelo controle de constitucionalidade das leis, por meio das ações diretas de inconstitucionalidade, ou mediante recursos.

O fato de o constituinte de 1988 constitucionalizar assuntos de natureza econômica, segundo Arantes e Couto (2004), reduziria a margem de manobra decisória dos atores políticos, ou seja, do legislativo e do executivo. A competição continuaria sendo viabilizada por meio de eleições, entretanto, ficaria restrita por imposições constitucionais aos governos eleitos. Ademais, a constitucionalização da ordem econômica abriu a possibilidade no Brasil, país adepto ao controle de constitucionalidade das leis, de o judiciário ser acionado para manifestar-se quanto à constitucionalidade ou não de algum programa, meta ou objetivo de governo que deverão estar vinculados por uma emenda constitucional ou a uma lei infraconstitucional.

Na mesma linha de raciocínio é a opinião de Grau (2003, p. 26), pois a legalização ou constitucionalização das políticas públicas induz à profusão de 
regras jurídicas, alterando a própria lógica do direito, que passa a regulamentar situações conjunturais ao invés de ordenar a estrutura do Estado, fato que acarreta maior flexibilidade e possibilidade de revisão das normas jurídicas. Nesse sentido, pode-se afirmar que o Estado não mais interviria na sociedade como o produtor do direito, mas que "passa a desenvolver novas formas de atuação, para o quê faz uso do direito positivo como instrumento de implementação de políticas públicas".

Essa revisão das normas apontadas por Grau pode se dar por meio de um novo governo eleito, ao propor alterações constitucionais e legais, ou mesmo por intermédio do poder judiciário, órgão responsável por verificar a validade ou não de uma lei, seja referente a questões estruturais de um Estado, seja com relação a assuntos conjunturais, como as políticas públicas de comunicação.

Partindo-se desse raciocínio, tem-se a redução da política, em especial as políticas públicas, às normas constitucionais.

Em decorrência desse fenômeno de alteração do direito, em especial com a constitucionalização das políticas públicas, Streck (2002) aponta que o centro de decisões desloca-se visivelmente do legislativo e do executivo para o judiciário, em especial, para o plano da jurisdição constitucional.

Ainda, segundo Streck (2004), existem dois eixos analíticos acerca dessa alteração no papel das constituições e, em consequência, sobre o papel a ser exercido pelo judiciário nesse novo modelo constitucional.

O primeiro eixo analítico considera a constituição como um mero instrumento de governo, ao definir e regular procedimentos político-administrativos 
e o segundo que compreende a constituição como sendo um documento que além de dispor de regras procedimentais também assegura valores e direitos substantivos.

Para o segundo eixo analítico, o judiciário deveria desempenhar o papel de intérprete desses direitos e valores substantivos previstos na constituição, como também precisaria assumir uma atitude ativa para a sua realização quando esses objetivos não forem alcançados pelos poderes políticos.

Entretanto, para alguns autores, como são os casos de Faria (2004) e Habermas (2003) não cabe ao judiciário suprir ou substituir as falhas decisórias dos outros poderes, até mesmo pelo fato de o judiciário ser apenas responsável pela aplicação da lei, tendo em vista que o modo de decisão do judiciário "é binário, pois suas estruturas só estão preparadas para decidir entre o legal e o ilegal, o constitucional e o inconstitucional" (FARIA, 2004, p. 111).

Para Habermas (2003, v. 2), o sistema de justiça somente poderia utilizar de argumentos que lhe são dados, seguindo o direito e a lei, para se definir os casos concretos de forma coerente.

Segundo esses autores, não caberia ao judiciário interpretar as decisões políticas, pois a esse poder, na estrutura de divisão de poderes, cabe-lhe, precipuamente, a aplicação da lei a um caso concreto.

Entretanto, como já foi dito, é uma peculiaridade do constitucionalismo brasileiro a elevação das políticas públicas a direito constitucional fato que, por si só, alarga sobremaneira o leque de ações do poder judiciário, pois este será, inevitavelmente, acionado para dirimir conflitos tendo em vista a aplicação ou não de uma política pública. 
Na ADPF 130 o Supremo foi acionado para manifestar-se sobre a constitucionalidade da lei de imprensa, conforme segue.

\section{A Arguição de Descumprimento de Preceito Fundamental 130}

A ADPF 130 foi proposta pelo Partido Democrático Trabalhista - PDT, em 19 de fevereiro de 2008, questionando na ação a constitucionalidade da lei federal n. 5.250, de 9 de fevereiro de 1967, que dispõe sobre liberdade de manifestação do pensamento e de informações.

O partido contestou inúmeros artigos da referida lei, alegando que os mesmos não foram recepcionados pela nova ordem constitucional de 1988, em especial pelos artigos $5^{\circ}$, IV , V, IX, X, XIII e XIV e 220 a 223. O PDT fez alegações pontuais de incompatibilidade para cada artigo da lei, como exemplo e apenas a título de ilustração, o partido questionou a constitucionalidade da parte inicial do $\S 2^{\circ}$ do artigo $1^{\circ}$, que dispunha que espetáculos e diversões públicas "ficarão sujeitos à censura, na forma da lei", como também questionou na integralidade os artigos 20, 21 e 22 da lei de imprensa que previa, respectivamente, os crimes de calúnia, difamação e injúria, com penas mais graves quando cometidos via imprensa. Postulou também pedido alternativo requerendo a declaração da incompatibilidade total da lei com a atual constituição. O cerne da discussão, portanto, estava relacionado à recepção ou não da lei de imprensa pela nova constituição.

O processamento da ação deve os seguintes acontecimentos processuais: a ação foi ajuizada em 
19/02/2008, sendo distribuída, na mesma data, ao Ministro Carlos Ayres de Britto para relatoria.

Em 21/2/2008 foi concedida liminar, confirmada por maioria pelo plenário seis dias depois. Em 1/4/2009 foi apresentado o relatório e iniciado o julgamento, votando o relator pela procedência do pedido, acatando os argumentos do partido. Nessa data, o Ministro Eros Grau antecipou seu voto, seguindo o relator. O julgamento foi interrompido, retornando à pauta em 30 de abril quando foi encerrado.

O Ministro relator Carlos Britto, após apresentar o seu relatório, proferiu voto no sentido de admitir a alegada inconstitucionalidade. Os argumentos do Ministro relator serão exibidos aqui em breve resumo.

Ayres Britto inicia o seu voto abordando questões conceituais sobre a imprensa e tecendo comentários acerca da importância de uma imprensa livre e a relação que ela mantém com a democracia, uma relação mútua de dependência e retroalimentação. Para o relator, a constituição garante direitos relacionados à atividade da imprensa no artigo $5^{\circ}$ e nos artigos 220 e 223. Os direitos previstos no artigo $5^{\circ}$ configurariam uma espécie de sobredireitos, sendo somente possível cobrar-se (definir) situações jurídicas decorrentes desses sobredireitos a posteriori. Nesse sentido, "para a Constituição, o que não se pode é, por antecipação, amesquinhar os quadrantes da personalidade humana quanto aos seguintes dados de sua própria compostura jurídica: liberdade de manifestação do pensamento e liberdade de expressão em sentido genérico".

Dessa forma, somente se garantiria esses direitos em sua plenitude, "colocando em estado de momen- 
tânea paralisia a inviolabilidade de certas categorias de direitos subjetivos fundamentais, como, por exemplo, a intimidade, a vida privada, a imagem e a honra de terceiros". Completa dizendo que em matéria constitucional "quem quer que seja pode dizer o que quer que seja" sem restrições a priori.

De acordo com o voto, a liberdade de imprensa seria o núcleo duro do texto constitucional, não sendo permitido ao Estado legislar de antemão sobre tais direitos, muito menos no intuito de restringi-lo. Haveria uma proibição ao poder legislativo, não podendo a lei e a emenda à constituição interferir no exercício desse direito. A interação entre a sociedade civil e a imprensa não poderia ser mediada pelo Estado.

Ademais, o texto constitucional garantiria aos direitos relacionados à liberdade de expressão uma "hierarquia axiológica", uma "primazia político-filosófica", não podendo a lei "dispor sobre as coordenadas de tempo e de conteúdo das liberdades de pensamento e de expressão ... pois esse tipo de interposta ação estatal terminaria por relativizar o que foi constitucionalmente concebido como absoluto". Esses direitos seriam "normas irregulamentáveis".

Disse o relator que "A atual Lei de Imprensa foi concebida e promulgada num prolongado período autoritário ... conhecido como 'anos de chumbo' ou 'regime de exceção'. Regime de exceção escancarada ou vistosamente inconciliável com os arejados cômodos da democracia..."

O voto do relator foi acompanhado, na íntegra, pelos Ministros Celso de Mello, Cezar Peluso, Eros Grau, Ricardo Lewandowski, Cármen Lúcia, e Menezes Direito, e, parcialmente, pelos Ministros Joaquim Barbo- 
sa, Ellen Gracie e Gilmar Mendes. O Ministro Marco Aurélio votou pela improcedência total do pedido.'

\section{Método e técnicas da pesquisa}

A análise de conteúdo foi a metodologia escoIhida para cumprir o objetivo da pesquisa que ora se relata. Essa metodologia, de acordo com Bardin (2011, p. 15), trata-se de um "conjunto de instrumentos metodológicos cada vez mais sutis em constante aperfeiçoamento, que se aplicam a 'discursos' extremamente diversificados", consiste, portanto, em "uma hermenêutica controlada, baseada na dedução" do pesquisador hermeneuta e pauta-se pelo "rigor da objetividade e da fecundidade da subjetividade". Objetividade referente aos dados quantitativos e subjetividade pelas inferências do próprio pesquisador.

A análise de conteúdo visa, portanto, dois objetivos: superar as incertezas (deixa de ser uma interpretação pessoal) e enriquecimento da leitura do texto; e duas funções: heurístico (enriquece a exploração) e serve de prova para as afirmações (BARDIN, 2011, p. 35).

Essa metodologia de análise passa por três etapas: 1 - pré-análise, com a definição da base empírica da pesquisa; 2 - a exploração dos achados da pesquisa, consistente na categorização do material

\footnotetext{
As decisões no controle de constitucionalidade são tomadas pela maioria absoluta da casa. É necessário que pelo menos seis Ministros concordem com a alegação de inconstitucionalidade. As decisões nessas ações, portanto, são deliberações colegiadas, podendo delas participar todos os Ministros que compõem o Tribunal. No controle de constitucionalidade, contudo o quórum exigido para início dos trabalhos é de no mínimo oito, exigese maioria qualificada para início das discussões pela própria natureza do processo em questão.
} 
coletado; 3 - análise propriamente dita dos resultados, com as inferências e interpretações do analista.

Tendo em vista a metodologia escolhida, para cumprir o objetivo da pesquisa e considerando que a ADPF 130 foi julgada pelo STF em 30 de abril de 2009, o período da pesquisa ficou circunscrito ao ano de 2009, em especial, na semana que antecedeu e sucedeu o julgamento referido, o que, por hipótese, teria acarretado uma grande produção de gêneros jornalísticos pelos veículos investigados.

Os gêneros foram pesquisados nos sites das empresas jornalísticas Folha de S. Paulo: http://www.folha.vol.com.br/ e O Globo: http://busca.globo.com/ Busca/oglobo/? query=Pesquisar, buscando-se material para a pesquisa na versão on-line do jornal impresso. A escolha dos veículos de comunicação justificou-se por se tratarem de importantes jornais de âmbito nacional, de repercussão, inclusive, internacional e de grande circulação diária, conforme dados obtidos junto à Associação Nacional de Jornais (http://www. anj.org.br/) e ao Instituto Verificador de Circulação (http://www.ivcbrasil.org.br/).

Observe-se que quando da realização da pesquisa a Folha de S. Paulo ocupava o segundo lugar em circulação diária, enquanto o $\bigcirc$ Globo ocupava o quinto. Por um dos critérios estabelecidos - jornais de âmbito nacional - foram excluídos os diários Super Notícia e Daqui, por serem considerados na proposta da pesquisa de âmbito local, respectivamente, Minas Gerais e Goiás, mesmo sendo impressos de grande circulação. Também foi excluído da investigação o O Estado de S. Paulo, tendo em vista que o jornal era parte interessada em um dos julgamentos objeto de análise na pesquisa principal, a saber: Reclamação n. 
9.428 envolvendo o O Estado de S. Paulo e Fernando José Maciel Sarney.

Considerando ainda o recorte temporal, o período pesquisado foi de 23 de abril a 7 de maio de 2009 .

Como a unidade de amostragem foram as edições do jornal no período mencionado, tem-se que as unidades de registro foram os gêneros jornalísticos produzidos nas edições selecionadas. Da mesma forma, a unidade de contexto foi a própria decisão do Supremo já citada.

Tendo em vista os objetivos da pesquisa, foram formuladas cinco categorias para o tratamento do material coletado: 1 - liberdade de expressão, 2 - democracia, 3 - autoritarismo, 4 - censura e 5 - papel/ funções do Supremo Tribunal Federal/judiciário.

A escolha das categorias 1 e 5 justifica-se, pois estão diretamente atreladas ao objetivo principal da pesquisa que visava investigar como os jornais escoIhidos trataram a decisão do STF, em especial, no que dizia respeito ao exercício do direito fundamental à liberdade de expressão do pensamento e à atuação do Supremo Tribunal Federal nessas questões. A escolha da categoria 2 justifica-se, tendo em vista que na própria decisão do STF há a indicação de que a democracia tem uma relação mútua de dependência e retroalimentação com a imprensa e com a liberdade de expressão. Da mesma forma, a escolha das categorias 3 e 4 justifica-se, pois ficou assentado no julgamento do STF que a lei de imprensa foi promulgada durante o período autoritário, um regime de exceção, vigorando pois, como regra, a censura. Tendo em vista a escolha dessas categorias, entendeu-se necessário conceituá-las, mesmo que resumidamente, conforme segue: 
1 - liberdade de expressão e seus sentidos correspondentes (liberdade de imprensa, de opinião, imprensa livre): considerada aqui como o direito fundamental que qualquer pessoa tem de exteriorizar, sob qualquer forma, o que pensa sobre qualquer assunto (SILVA, 2010). Na liberdade de expressão está contida a liberdade de opinião, reconhecida como a liberdade de expressão primária, que consiste na prerrogativa da pessoa de adotar a postura intelectual que quiser e, se for da sua vontade, exteriorizar essa opinião por qualquer meio, por intermédio dos meios de comunicação, das artes, das ciências, das religiões, das pesquisas científicas, compreendendo também a liberdade de informação em geral. $\bigcirc$ direito à liberdade de expressão garante até mesmo a liberdade do indivíduo, se desejar, de não expressar a sua opinião.

2 - democracia: considerada como o "regime de garantia geral para a realização dos direitos fundamentais do homem" (SILVA, 2010, p. 132), dos quais a liberdade faz parte, sendo a liberdade de expressão do pensamento a maior expressão da liberdade.

3 - autoritarismo e seus correlatos (autoritário, ditadura, período de exceção, anos de chumbo): a contrário sensu, pode ser considerado o regime político que não garante a realização dos direitos fundamentais do homem, como é o caso da liberdade de expressão do pensamento.

4 - censura: oposição à liberdade de expressão do pensamento e em consequência com a democracia (NAPOLITANO, LUVIZOTTO E GONZALES, 2004) ou em outros termos, toda a forma de intervenções do Estado que tem por objetivo impedir a divulgação 
por qualquer meio, processo ou veículo de conteúdos políticos, ideológicos ou artísticos.

5 - papel/funções do Supremo Tribunal Federal/ judiciário: guardião do texto constitucional e agente na efetivação de políticas públicas de comunicação.

Observe-se, que em relação à última categoria, que a preocupação da pesquisa, no que diz respeito ao papel do STF, consistiu na análise do denominado diálogo externo do STF com a sociedade civil organizada e, em especial, com os meios de comunicação social. A análise que se pretendeu, portanto, era a da deliberação externa do STF, que de acordo com Silva (2009, p. 210 e $211 / 212)$, trata-se de um esforço do Supremo de convencimento dos "atores externos ao grupo", ou, em outros termos, consistiria no "chamar a atenção da sociedade civil, ou pelo menos da comunidade acadêmica e jornalística, para questões fundamentais no cenário político-jurídico de um país", como foi o caso da declaração de não recepção da lei de imprensa.

Considerando o que já foi apresentado e os objetivos da pesquisa, no período foram localizados e analisados nove gêneros jornalísticos publicados pelo jornal Folha de S. Paulo, sobre o julgamento da ADPF 130 pelo Supremo Tribunal Federal, conforme tabela a seguir e espécies jornalísticas. 
Tabela 1 - Pesquisa sobre ADPF 130 - Folha de S. Paulo

\begin{tabular}{|c|c|c|c|c|}
\hline Data & Título & Espécie & $\begin{array}{l}\text { Caderno/ } \\
\text { Seção }\end{array}$ & Autor \\
\hline $\begin{array}{l}30 \text { de abril } \\
\text { / quinta- } \\
\text { feira }\end{array}$ & $\begin{array}{l}\text { Sessão de hoje do STF deve revogar } \\
\text { Lei de Imprensa: Manutenção de } \\
\text { regras sobre direito de resposta é } \\
\text { dúvida. }\end{array}$ & Notícia & Brasil & \\
\hline $\begin{array}{l}1^{\circ} \text {. de maio } \\
\text { / sexta- } \\
\text { feira }\end{array}$ & $\begin{array}{l}\text { STF decide pela revogação de toda a } \\
\text { Lei de Imprensa - Decisão de ontem } \\
\text { abre vácuo jurídico em relação à } \\
\text { garantia do direito de resposta - } \\
\text { Temas de imprensa serão tratados } \\
\text { pelos códigos Civil e Penal e } \\
\text { pela Constituição; processos em } \\
\text { andamento deverão ser migrados. }\end{array}$ & Notícia & Brasil & \\
\hline $1^{\circ}$. de maio & $\begin{array}{l}\text { Direito de resposta: fim de regras vai } \\
\text { levar à "autorregulação", diz Mendes. }\end{array}$ & Nota & Brasil & \\
\hline $1^{\circ}$. de maio & Para ANJ, resultado foi positivo. & Notícia & Brasil & \\
\hline $1^{\circ}$. de maio & $\begin{array}{l}\text { Maioria dos países tem lei, mas EUA } \\
\text { não. }\end{array}$ & Notícia & Brasil & \\
\hline $\begin{array}{l}2 \text { de maio - } \\
\text { sábado }\end{array}$ & $\begin{array}{l}\text { Congressistas divergem sobre nova lei } \\
\text { para direito de resposta. }\end{array}$ & Notícia & Brasil & \\
\hline $\begin{array}{l}3 \text { de maio - } \\
\text { domingo }\end{array}$ & $\begin{array}{l}\text { Direito à informação - Decisão do STF } \\
\text { que anulou Lei de Imprensa produz } \\
\text { incerteza e alguns riscos para a } \\
\text { liberdade que se quis defender. }\end{array}$ & Editorial & Opinião & \\
\hline $\begin{array}{l}5 \text { de maio - } \\
\text { terça-feira }\end{array}$ & Informação é poder. & Artigo & Opinião & $\begin{array}{l}\text { Marcos } \\
\text { Nobre }\end{array}$ \\
\hline 5 de maio & Leis de prensa. & Artigo & Brasil & $\begin{array}{l}\text { Jânio de } \\
\text { Freitas }\end{array}$ \\
\hline
\end{tabular}

Da mesma forma, nove gêneros jornalísticos foram publicados pelo $\bigcirc$ Globo, no período pesquisado, conforme segue. 
Tabela 2 - Pesquisa sobre ADPF 130 - O Globo

\begin{tabular}{|c|c|c|c|c|}
\hline Data & Título & Espécie & Caderno/Seção & Autor \\
\hline $01 / 05 / 2009$ & $\begin{array}{l}\text { Supremo revoga } \\
\text { lei de imprensa. }\end{array}$ & Notícia & Primeiro Caderno/O País & \\
\hline $01 / 05 / 2009$ & $\begin{array}{l}\text { Direito de resposta } \\
\text { terá de ser } \\
\text { regulado. }\end{array}$ & Nota & Primeiro Caderno/O País & \\
\hline $01 / 05 / 2009$ & $\begin{array}{l}\text { ANJ e Fenaj } \\
\text { aprovam } \\
\text { revogação, mas } \\
\text { querem regras } \\
\text { para direito de } \\
\text { resposta. }\end{array}$ & Notícia & Primeiro Caderno/O País & \\
\hline $01 / 05 / 2009$ & Lei é da ditadura. & Nota & Primeiro Caderno/O País & \\
\hline $01 / 05 / 2009$ & $\begin{array}{l}\text { Miro: direito à } \\
\text { informação é } \\
\text { absoluto. }\end{array}$ & Nota & Primeiro Caderno/O País & \\
\hline $02 / 05 / 2009$ & Antes que tardia. & Editorial & Primeiro Caderno/O País & \\
\hline $06 / 05 / 2009$ & $\begin{array}{l}\text { Senado vai regular } \\
\text { direito de resposta. }\end{array}$ & Notícia & Primeiro Caderno/O País & \\
\hline $06 / 05 / 2009$ & $\begin{array}{l}\text { SIP elogia fim da } \\
\text { lei de imprensa. }\end{array}$ & Nota & Primeiro Caderno/O País & \\
\hline $07 / 05 / 2009$ & O que fazer? & $\begin{array}{l}\text { Artigo } \\
\text { de } \\
\text { opinião }\end{array}$ & Primeiro Caderno/O País & $\begin{array}{l}\text { Luiz Gustavo } \\
\text { Grandinetti } \\
\text { Castanho de } \\
\text { Carvalho }\end{array}$ \\
\hline
\end{tabular}

\section{Considerações sobre os achados da pesquisa}

\section{Análise quantitativa - Folha de S. Paulo}

Considerando os aspectos meramente quantitativos da pesquisa, no período pesquisado foram localizados nove gêneros jornalísticos sobre o julgamento da ADPF 130 na Folha de S. Paulo, concentrando-se as veiculações no dia posterior ao julgamento, o que corresponde a $44 \%$ do total, conforme se verifica na tabela 1 acima, havendo um arrefecimento dos conteúdos dias após a decisão, concentrando as abordagens em forma de editorial e artigos opinativos nos dias que se seguiram. 
Considerando-se as categorias já elencadas, nos nove gêneros publicados pela Folha de S. Paulo no período analisado, ocorreram as seguintes incidências: democracia (1); autoritarismo (0), ditadura (2), período de exceção (1), anos de chumbo (1), total (4); liberdade de expressão (2), liberdade de imprensa (7), total: (9); censura (8); papel/função do STF/ judiciário (2).

\section{Análise qualitativa Folha de S. Paulo}

Em relação ao conteúdo, chama atenção a preocupação da Folha de S. Paulo com um eventual vácuo legislativo decorrente da decisão do STF. Trata-se da ausência de normas infraconstitucionais regulamentadoras do direito de resposta. ${ }^{2}$ Essa preocupação foi expressa na matéria publicada no dia seguinte à decisão do STF, com o título "STF decide pela revogação de toda a Lei de Imprensa". Esse receio da empresa de comunicação está indicado no subtítulo (Decisão de ontem abre vácuo jurídico em relação à garantia do direito de resposta), bem como no corpo da matéria.

A opinião do jornal sobre essa suposta lacuna legislativa fica evidente no editorial (Direito à informação - Decisão do STF que anulou Lei de Imprensa produz incerteza e alguns riscos para a liberdade que se quis defender) publicado no dia 3 de maio.

2 Em 11 de novembro de 2015, foi publicada e entrou em vigor a nova lei que regulamenta o direito de resposta, trata-se da lei $n$. 13.188/15. Referida lei foi questionada junto ao Supremo Tribunal Federal quanto à sua constitucionalidade pelas Ações Diretas de Inconstitucionalidade números 5.415 e 5.436, respectivamente propostas pelo Conselho Federal da Ordem dos Advogados do Brasil e pela Associação Nacional dos Jornais. 
Observe-se que essa questão acerca do direito de resposta foi polemizada no próprio STF. Os votos divergentes do relator, em sua grande maioria, três dos quatro votos divergentes, diziam respeito a essa questão pontualmente.

Chama a atenção ainda a ideia lançada no editorial sobre a necessidade do Congresso Nacional elaborar uma nova lei de imprensa, qualificada como "plenamente democrática". A mesma sugestão foi apontada pelo jornalista Jânio de Freitas em seu texto "Leis de prensa".

Segundo o articulista, "o debate em torno de alguma legislação nova ou não, inovadora ou não, conviria acelerar-se". A FENAJ endossa essa opinião, de acordo com a Folha de S. Paulo "O presidente da Fenaj (Federação Nacional dos Jornalistas), Sérgio Murillo de Andrade, criticou a decisão. 'Esse resultado aumenta a dívida que o Congresso tem de votar o mais rápido possível uma nova lei'". A necessidade de nova regulamentação também está implícita na nota "Maioria dos países tem lei, mas EUA não", nos seguintes termos: "A maioria dos países democráticos tem algum tipo de lei de imprensa. Nos EUA, no entanto, não há uma legislação específica".

Marcos Nobre também propõe a necessidade de se discutir uma nova regulamentação, na expressão do colunista, "uma Lei da Informação".

Essas colocações deixam em evidência a preocupação do jornal e de seus colunistas com a hipótese de lacuna legislativa decorrente da não recepção da lei de imprensa.

No que diz respeito ao papel do judiciário e do STF, em duas matérias do jornal o tema foi tratado. Por se tratar de um dos objetivos específicos da pes- 
quisa, serão transcritos a seguir trechos das publicações do jornal acerca da temática.

Em editorial (Direito à informação) a Folha de S. Paulo põe em xeque a justiça brasileira, em especial, a de primeira instância. De acordo com a empresa:

Resultou minoritária a tese de que certos artigos do diploma deveriam ser mantidos. Seria esta, na verdade, a decisão mais apta a garantir o pleno direito à informação. Embora a Constituição o assegure plenamente, na legislação civil e penal há dispositivos capazes de inspirar empecilhos a esse princípio, em especial quando casos duvidosos são julgados em primeira instância. Já se registraram, nessa esfera judicial, decisões em favor do recolhimento de biografias publicadas, supostamente por conterem material ofensivo à memória de personalidades reais. A censura prévia e a intimidação judicial sobre publicações menores e independentes - ou sobre indivíduos que, cada vez mais, se valem da internet para fazer jornalismo e emitir suas opiniões - tornam-se assim um risco. Na falta do núcleo não autoritário da lei, decisões relativas às várias formas de manifestação da imprensa estão entregues, a partir de agora, a interpretações fragmentárias e por vezes intempestivas de juízes singulares.

Marcos Nobre também aborda o tema, enfrentando-o de forma direta relativamente às funções do STF. Para o articulista:

E mais uma vez se diz que o julgamento do STF é uma intromissão indevida na atividade do Congresso. E mais uma vez é preciso lembrar que o STF está cumprindo uma de suas legítimas funções, que é a de fornecer à sociedade a imagem mais íntegra possível da Constituição. É verdade que, antes de 2005, o tribunal desempenhou esse papel de maneira episódica apenas. Mas há que considerar que pelo menos dez anos se 
passaram desde a promulgação até que as diferentes forças políticas aceitassem a Constituição como legítimo horizonte compartilhado de atuação. Além disso, a onda de reformas constitucionais de 1994 a 2004 tornou instável o texto constitucional, o que impediu naquele período uma tentativa de interpretação de conjunto coerente e consequente. O momento atual parece já adequado para que isso possa ocorrer.

Verifica-se no editorial a inquietação do jornal em relação ao direito à informação e às limitações que a justiça possa impor a esse direito quando em confronto com outros direitos fundamentais. Põe em dúvida ainda a justiça de primeira instância e a possibilidade de "interpretações fragmentárias e por vezes intempestivas de juízes singulares". O mote para esse questionamento eram as proibições pela justiça de primeiro grau de divulgação de biografias não autorizadas, assunto julgado pelo Supremo Tribunal Federal em 2015 (ADI 4.815).

O articulista da Folha Marcos Nobre, por sua vez, aborda a questão da guinada do judiciário brasileiro, dizendo que até meados da década de 2000 - STF era tímido em suas decisões e que após esse período a atuação do Supremo passa a ter destaque. Descarta também a ideia de que o STF se intromete indevidamente em determinadas questões, como no caso da Lei de Imprensa, e vai além defendendo expressamente essa possibilidade de atuação, afirmando que "O momento atual parece já adequado para que isso possa ocorrer".

\section{Análise quantitativa $\bigcirc$ Globo}

Considerando os aspectos meramente quantitativos da pesquisa, no período pesquisado foram loca- 
lizados nove gêneros jornalísticos sobre o julgamento da ADPF 130 no jornal O Globo, concentrando-se as veiculações no dia posterior ao julgamento, o que corresponde a 55\% do total, conforme se verifica na tabela 2 acima. De modo diferente do que foi observado na Folha de S. Paulo, dias após o julgamento o O Globo volta a noticiar sobre a decisão do STF, além de publicar editorial e artigo de opinião a respeito do assunto.

Considerando-se as categorias já elencadas, nos nove gêneros publicados pelo $O$ Globo ocorreram mais incidências dos temas liberdade de expressão (7) e autoritarismo (6), para o tema censura e papel do STF não houve incidência e a democracia foi mencionada uma vez.

\section{Análise qualitativa $\bigcirc$ Globo}

Especificamente em relação aos gêneros, as notícias divulgadas no dia subsequente ao julgamento, relataram basicamente o julgado e o posicionamento individual de cada um dos ministros da corte.

Tanto na notícia "Supremo revoga lei de imprensa" quanto na nota "Direito de resposta terá de ser regulado" a principal questão tratada pelo jornal dizia respeito ao vácuo legislativo criado pela ausência de regulação do direito de resposta, com o fim da lei de imprensa.

Esse assunto também foi a grande questão tratada em todos os textos publicados, após o julgamento. Essa temática fica evidente, considerando-se os títulos "Direito de resposta terá de ser regulado" e "ANJ e Fenaj aprovam revogação, mas querem regras para direito de resposta". 
No único editorial localizado acerca da decisão denominado "Antes que Tardia" o jornal classifica a Lei de Imprensa como o "último dos grandes entulhos autoritários herdados" do período militar. Define ainda que a manutenção da lei no período de 1988 a 2009 era considerada como um "zumbi inconstitucional". O jornal endossa a ideia do vácuo legislativo criado em relação ao direito de resposta e indica ainda a necessidade de definição de critérios para o pagamento de indenizações. O veículo se preocupa com o que diz ser um "excesso" dos juízes de primeira instância, em especial, no interior do país na concessão do direito de resposta e na fixação das indenizações.

Na notícia "Senado vai regular direito de resposta" o jornal apresenta as posições da FENAJ e da ANJ sobre a regulação do direito de resposta. A entidade empresarial mostra-se favorável à regulação, ao passo que a entidade profissional espera por uma nova regulação da imprensa e não somente uma lei que trate exclusivamente do direito de resposta.

No artigo de opinião "O que fazer?" o articulista demonstra perplexidade com o fim da regulação infraconstitucional do direito de resposta e sugere que na ausência de regras específicas poderia ser utilizado o Código de Defesa do Consumidor, especificamente, no que se refere à contrapropaganda. Sugere ainda a criação do direito de resposta coletivo, que poderia ser utilizado pela sociedade e não mais somente por indivíduos ou grupos, conforme estabelecia a lei.

\section{Considerações finais}

Do que foi mencionado, pode-se concluir com a pesquisa que os veículos pesquisados deram pouco destaque à decisão, preocupando-se basicamente 
com a descrição e apresentação da ADPF 130, tendo em vista que a grande maioria dos gêneros jornalísticos foi produzido no dia imediatamente subsequente à deliberação do STF acerca da lei de imprensa.

Verifica-se também que apesar dos conteúdos terem enfrentado as temáticas da liberdade de expressão/censura e democracia/liberdade de expressão, conforme incidências das categorias levantadas, esses temas não foram abordados, sendo certo que a preocupação central das empresas de comunicação estava relacionada com a hipotética lacuna legislativa criada pela não recepção da lei de imprensa, em especial, sobre o direito de resposta e pela ausência de regras claras e específicas acerca de eventuais indenizações por abusos cometidos.

Por fim, considera-se que pouca atenção foi dada para a função do STF/judiciário, em sentido oposto, verifica-se que os veículos questionam o papel e atuação dos juízes de primeiro grau, indicando até mesmo alguns excessos cometidos por juízes na concessão do direito de resposta e na fixação de indenizações, sugerindo um cenário de insegurança jurídica que pode ser ocasionado por decisões fragmentárias a respeito de um mesmo assunto, como seria o caso das bibliografias não autorizadas.

\section{Referências}

ARANTES, R. B. e COUTO, C. G. Constituição, governo e democracia no Brasil. In: Encontro anual da Anpocs, n. 28, 2004, Caxambu.

BARDIN, L. Análise de conteúdo. São Paulo: Edições 70, 2011.

COUTINHO, D. R. O direito nas políticas públicas. In: MARQUES, E.; FARIA, C. A. P. de (Orgs.). A política pública como campo multidisciplinar. São Paulo: Ed. UNESP; Rio de Janeiro: Ed. Fiocruz, 2013. 
FARIA, J. E. O sistema brasileiro de justiça: experiência recente e futuros desafios. Estudos Avançados, São Paulo, v. 18, n. 51, p. 103-125, 2004.

FONSECA JUNIOR, W. C. da. Análise de conteúdo. In: DUARTE, J. e BARROS, A. (Orgs.). Métodos e técnicas de pesquisa em comunicação, 2. ed. São Paulo: Atlas, 2011.

GRAU, E. R. O direito posto e o direito pressuposto, 5. ed. São Paulo: Malheiros, 2003.

HABERMAS, J. Direito e democracia: entre facticidade e validade. Rio de Janeiro: Tempo Brasileiro, 2003, 2v.

MARQUES DE MELO, J.; ASSIS, F. A natureza dos gêneros e formatos jornalísticos. In: SEIXAS, L.; PINHEIRO, N. F. (Orgs.). Gêneros: um diálogo entre comunicação e linguística. Florianópolis: Insular, 2013.

NAPOLITANO, C. J., LUVIZOTTO, C. K.; GONZALES, L. dos S. Censura à liberdade de expressão e propaganda política: estratégias para legitimação do regime militar. In: Napolitano, C. J., Luvizotto, C. K., Losnak, C. J., Goulart, J. O. (Orgs.). O Golpe de 1964 e a Ditadura Militar em Perspectiva. São Paulo: Cultura Acadêmica, 2014.

SILVA, J. A. Curso de direito constitucional positivo, 33. ed. São Paulo: Malheiros, 2010.

SILVA, V. A. da. O STF e o controle de constitucionalidade: deliberação, diálogo e razão pública. RDA, 250, p. 197-227, 2009.

Interpretação constitucional e sincretismo metodológico. In:

2010. (Org.). Interpretação constitucional. São Paulo: Malheiros,

STRECK, L. L. Jurisdição constitucional e hermenêutica: uma nova crítica do direito. Porto Alegre: Livraria do advogado, 2002.

A permanência do caráter compromissório (e dirigente) da constituição brasileira e o papel da jurisdição constitucional: uma abordagem à luz da hermenêutica filosófica. RIPE, Bauru, n. 39, p. 75-119, jan./abr. 2004. 
A decisão do Supremo Tribunal Federal sobre a Lei de Imprensa na

Folha de S. Paulo e no O Globo

Carlo José Napolitano

Pós-Doutor pelo Departamento de Direito do Estado, da Faculdade de Direito, da Universidade de São Paulo, Doutor em Sociologia pelo Programa de Pós-Graduação em Sociologia da Faculdade de Ciências e Letras, UNESP/Araraquara, professor do Departamento de Ciências Humanas e do Programa de Pós-Graduação em Comunicação, da Faculdade de Arquitetura, Artes e Comunicação, UNESP/ Bauru/SP, e-mail: carlonapolitano@faac.unesp.br. 